\title{
Los pueblos originarios en el marco del desarrollo de sus derechos
}

José Antonio GonZÁlez P. ${ }^{1}$

\section{RESUMEN}

Se revisa el reconocimiento de los derechos de los pueblos originarios en Chile, desde la etapa de la independencia hasta la promulgación de la ley indígena en 1993. Se señalan los varios contextos ideológicos y acontecimientos históricos que explican de qué manera las variadas etnias del norte y sur del país han pasado desde procesos contradictorios de asimilación, integración, exclusión hasta el reconocimiento no sólo en lo legal sino en su aporte antropológico a la nación chilena.

Palabras claves: pueblos originarios - derechos - proceso histórico.

\section{ABSTRACT}

This article reviews the recognition of Chilean indigenous people's rights from the independence stage to the passing of the indigenous law in 1993. Several ideological contexts and historic events are referred to explaining how the country's varying southern and northern ethnic groups have gone from contradictory processes of assimilation, integration and exclusion to not only legal recognition but also recognition of their anthropological contribution to the Chilean nation.

Key words: indigenous people - rights - Chile - historic process.

Recibido: julio 2004. Aceptado: diciembre 2004.

"La humanidad no avanza ni retrocede en todos los campos, sino que manifiesta precisamente una bifurcación de los mismos: en un grupo de valores culturales se realizan continuos y brillantes progresos, mientras que en otros se encuentra ante el peligro de sufrir fatales retrocesos"

P. Wilhelm Schmidtt (cit. en Gusinde 2000).

1 Escuela de Derecho, Universidad Católica del Norte. Casi1la 1280, Antofagasta, CHILE. Email: jagonzal@ucn.cl

\section{Introducción}

El tema sobre los pueblos originarios en el marco del desarrollo de sus derechos, es una cuestión que, a estas alturas, no puede plantearse de modo lineal como un largo recorrido ascendente, respecto a la nación, al Estado, o a las propias disciplinas que estudian al hombre desde la fragmentación del saber. La sociedad cada vez se parcela en pos de identidades recónditas que mutatis mutandi conduce a la persona a plantearse una conciencia, no autorreferencial o abstracta, por el contrario, siempre respecto de algo. No bastan ya los derechos subjetivos de los grandes expositores de la filosofía política de los siglos XVII y XVIII, para poder asumir si todos somos iguales, libres, propietarios, porque aquellos postulados, también, como lo hacía presente el destacado filósofo y cientista político italiano recientemente fallecido, Norberto Bobbio, respondían a sectores sociales que pujaban por serle reconocidas aquellas facultades que estimaban como integrantes del derecho natural y, por ende, dibujaron un Estado a su imagen y semejanza: el Estado liberal que reemplazó al Estado absolutista. Empero, en la actualidad, nuevos referentes que cuestionan incisivamente la creación jurídica-política decimonónica, el Estado-nación, conducen a una exigencia que vuelve a situar a los pueblos originarios en el contexto de la vieja formulación hegeliana: el reconocimiento.

\section{Las ideas matrices sobre los naturales en los albores republicanos}

El asunto, en mi opinión, estriba en la siguiente paradoja: el Estado liberal, preconizado por el constitucionalismo inglés y la ilustración francesa, se basó en los ideales de la libertad y la igualdad, como fundamentos del derecho privado, y no alcanzó a cubrir los derechos del pueblo mapuche. Este pueblo originario estaba en goce de sus plenos derechos, por contar con el reconocimiento de su soberanía política. Esta contradicción se profundiza, en el siguiente sentido: mientras la Constitu- 
ción de 1818 reconocía, en su artículo $1^{\circ}$, que "los hombres por su naturaleza gozan de un derecho inajenable e inamisible a su seguridad individual, honra, hacienda y a su libertad e igualdad civil"; los mapuches, por el Parlamento de Quillín de 1641 eran reconocidos como pueblo soberano por el Estado español (Levaggi 2002; Szászdi y Palma 1998: 699-703). Fue el gran legado del Derecho Indiano. Más allá de las luces y sombras que al respecto se pueda tener de la presencia hispana en el suelo americano, acá es pertinente distinguir dos aspectos: uno, la situación sobre la capacidad jurídica de los indígenas en el Derecho Indiano y los pueblos de indios, dentro de la jurisdicción hispana; dos, la realidad del pueblo mapuche y la constitución de la "frontera" que distinguió claramente la soberanía de la etnia durante la Colonia e incluso, hasta la primera mitad del siglo XIX por el Gobierno de Chile, y que se evidencia en los denominados "Parlamentos" o pactos o acuerdos entre la monarquía hispana y la representación mapuche.

No hubo discusión alguna en nuestros próceres sobre los caracteres que asumía la organización política y social de aquellos pueblos al extremo meridional de la frontera del Bío Bío. Aquello fue tan obvio que el interés se canalizó en cómo integrar a estas etnias en la casa republicana. No hubo posibilidad alguna de debatir sobre el mentado criterio de la racionalidad aristotélica para cuestionar sus formas de vida, como de igual forma, no se pronunció palabra alguna sobre la entelequia del "estado de naturaleza" que tanto inquietó a Hobbes, a Locke y a Rousseau, pues para Bernardo O'Higgins, nuestros aborígenes, como se hizo constar en el Manifiesto de la Independencia, de febrero de 1818:

\section{"Ese miserable resto de indígenas, que ha podido sobrevivir a tantos millones de víctimas y que agitado en diversas tribus errantes, como los montones de arena en el desierto, conserva en sus elegías los fastos de su triste persecución, ¿no está acreditando su repugnancia al yugo de los agresores en esa guerra discontinua que mantie- ne siempre en movimiento las fronteras de nues- tras poblaciones?"(Valencia 1986: 20).}

Esta firme e inequívoca declaración se encaminó por la búsqueda de la integración política de los pueblos originarios. O’Higgins, como Ramón Freire, había convivido con el pueblo mapuche.
Nuestro principal prócer de la gesta emancipadora hablaba mapundungun y se había educado en el Colegio de Naturales de Chillán.

Los pueblos originarios quedaron sujetos a disposiciones de derecho público con elementos que regulaban la vida privada, en los primeros años de aire emancipador. Es una conjunción de miradas que devela matices etnocéntricos con la propensión de los anhelos republicanos.

La Junta de Gobierno de 1813 ya declaraba hacer:

“... efectivos los ardientes conatos con que proclama la fraternidad, igualdad y prosperidad de los indios y teniendo una constante experiencia de la extrema miseria, inercia, incivilidad en que viven abandonados en los campos, con el supuesto nombre de pueblos". ${ }^{2}$

Este reglamento reconocía que pudiesen gozar "de los mismos derechos sociales de ciudadanía que corresponde al resto de los habitantes" y señala, sinuosamente, que los eventuales remates públicos de los pueblos de indios y sus productos deberían favorecer a cada familia de indios, con bueyes, arado, semillas. Empero, un senado consulto de 4 de marzo de 1819 otorgó plena capacidad civil a los indígenas.

Repárese, por ejemplo, cómo, en tiempos de O'Higgins, nos encontramos con la idea-fuerza de la asimilación étnica-jurídica-política de nuestros aborígenes: un decreto de 3 de junio de 1818, al mudar la denominación "español" por la de "chile-

2 Este interesante Reglamento-Ley refiere en su preámbulo "Deseando el Gobierno hacer efectivos los ardientes conatos con que proclama fraternidad, igualdad i prosperidad de los indios, i teniendo una constante experiencia de la estrema miseria, inercia, incivilidad, falta de moral i educación en que viven abandonados en los campos, con el supuesto nombre de pueblos, i que, a pesar de las providencias que hasta ahora se han tomado i (tal vez por ellas mismas) se aumenta la degradación i vicios, a que también quedaría condenada su posteridad, que debe ser el ornamento de la patria" y en el apartado XI refiere, "El Gobierno conoce que entre la clase ruda, abandonada i miserable de los indios i los hacendados poderosos que los rodean...siempre las usurpaciones i transgresiones de deslindes deben haberse dimanado i verificado con provecho de las personas pudientes; que, por consiguiente, los pleitos de restitución i saneamiento regularmente cederán a favor del Fisco" (Anguita 1912, I: 39-40). 
no" refiere que no "debe hacerse diferencia alguna (de los indios), sino denominarlos chilenos"; en marzo de 1819 se les reconocía la ciudadanía con lo que tendrían igual voz y representación. Ese mismo año, O'Higgins da a conocer su "Proclama a los habitantes de la frontera del país". Su objetivo es restablecer los pactos de alianzas con los araucanos, serruchos, huilliches y todas las tribus australes, a los que exhorta:

"No hay ni puede haber una razón que nos haga enemigos, cuando descendemos todos de unos mismos padres, habitamos bajo un clima y las producciones de nuestro territorio, nuestros hábitos y nuestras necesidades respectivas, nos invitan a vivir en la más inalterable buena armonía $y$ fraternidad".

Nos atreveríamos a indicar que se está viviendo la euforia del replanteamiento de nuestros ancestros por parte de criollos que han desvinculado el territorio y sus gentes de la monarquía española. La ruptura en la sociedad chilena, una guerra civil en vez de una guerra contra España, requiere legitimarse de cara con la nación: la legitimidad social atisba a buscar los ideales y la continuidad histórica con nuestros ancestros y abominar de los padres de los criollos. Aquello lo dice, con énfasis y con letras de fuego, nada menos el Manifiesto de Independencia. Y nos hemos olvidado de este documento que inaugura la reconstrucción social de la nación chilena.

Todo respira de una añoranza por lo autóctono: nuestros emblemas del período de José Miguel Carrera, la lectura de "La Araucana" de Ercilla, el redescubrimiento de nuestros cronistas dieciochescos que alumbraron este germen de protopatriotismo, nuestra estrella solitaria en nuestro emblema nacional, etc. (González P. 1996: 765). Los elementos diacríticos de nuestra identidad recogían lo primigenio (Larraín 2001).

Es un país que todavía se debate respecto al derecho indígena y, en general, sobre la situación de los pueblos originarios, entre un monismo jurídico atenuado, que si bien el Estado crea el derecho, reconoce la existencia de normas consuetudinarias en aquellas etnias, y un monismo jurídico que sólo justiprecia usos y costumbres en los pueblos ancestrales pero éstos carecen de derecho.
Es una realidad que nos desvía la mirada nacional. El reconocimiento, del cual hemos hablado, se torna hacia la identificación de la nación chilena en general, por parte del mundo europeo, y descuidamos internamente lo avanzado: no hay una simetría entre la construcción del Estado que abrigaban O'Higgins y otros patriotas, y lo buscado, después de 1833, por el Estado nacional que emerge en la constitución de aquel año.

Mientras el prócer escribe en octubre de 1830 al general J. J. Prieto: "Yo considero a los pehuenches, puelches y patagones por tan paisanos nuestros como los demás nacidos al norte del Bío Bío" (Pinto 2003: 65-66), lo que avalaba un reconocimiento e integración en condiciones de igualdad a la nación chilena, la realidad fue distinta. $\mathrm{La}$ concreción del denominado "Estado en forma", precisamente, durante el gobierno de Prieto, tomó otras orientaciones y referentes para abordar el asunto de la reconstrucción histórica y la formación de una identidad propia.

\section{El Estado liberal y su delineamiento jurídico respecto a los pueblos originarios}

Cuando en 1839 Mariano Egaña, ministro de Instrucción Pública, le encarga al ciudadano francés Claudio Gay una historia política de la nación, el ministro arguye cuatro razones para tal elaboración: dos apuntaban a dimensionar que la civilización española quedó salvada en Chile, ante el peligro inglés y holandés, y que la guerra de Arauco lesionó el concepto imperial castellano. Las otras dos eran afirmar la imagen de Chile como fundamental en el destino de América -remarcando el significado de las acciones en Chacabuco, Maipo y la expedición libertadora al Perú- y como el único país organizado con un sistema republicano y régimen jurídico (González P. 1990).

Se está en el límite de todo: todavía resonaban los ecos parlamentarios de construir una casa grande -que era la nación- y cobijar a todos, como de igual forma, Gay en su Prospecto de 1841 pensaba que su historia se podía "mirar como la historia de una gran familia". El Presidente Bulnes abrigaba la idea de integrar y civilizar a los mapuches y otras etnias mediante la persuasión y el respeto a sus pueblos. Las herramientas eran las consabidas: enfatizar el Estado misionero, con el auxilio de franciscanos y capuchinos, y el em- 
pleo de los Parlamentos coloniales que era reconocer dos entidades a la vez: la "diferencia" en pos de la asimilación, como cuerpo político independiente, y el "reconocimiento" a sus formas de vida, pero sometidas al imperio de la ley republicana.

En todo ello, habrá que sopesar que, a pesar de los intentos por propender a dotar de una igualdad en el amplio sentido a los mapuches, las élites y el Estado surgido en 1833 y proseguido durante el siglo XIX, se inclinaron por el monismo jurídico. El triunfo definitivo de éste se verificó mediante tres aspectos en la evolución del Estadonación: a) la promulgación del Código Civil en 1855 que significó virtualmente la desaparición de la costumbre como fuente formal del derecho; el Código buscó establecer "una sociedad de hombres más libres e iguales en el orden civil, sometidos, sin embargo, a la ley" (Guzmán 1982: I); b) la pérdida de la influencia de la Iglesia Católica en las esferas gubernamentales, ya en tiempo de José Joaquín Pérez M. (1861-1871). Esto se tradujo en la debilitación de la defensa del concepto de Bien Común y su reemplazo en la práctica por el Consenso y el Mercado, como definidores de la propiedad comunal de los pueblos originarios; y c) concomitante, con lo anterior, las ideas-fuerzas del positivismo comteano y el liberalismo económico, no sólo impulsaron el uso militar como opción de civilización sobre el territorio de la Araucanía, en 1862, con la refundación de Angol, sino al declarar nuestro Congreso en 1866 que el Estado se presupone dueño de las tierras mapuches, definió claramente las finalidades del Estado: la ocupación del territorio que culmina en 1883 , y la subasta pública de las tierras ancestrales.

Es importante reflexionar sobre estos hechos en la Región de la Araucanía. O'Higgins por ley de 4 de marzo de 1819 había abolido la institución del Protector indígena, con lo que se había logrado un "régimen de igualdad sin protección". Empero, la presión sobre el territorio meridional comenzaba con la ley de 18 de noviembre de 1845 sobre establecimiento de colonias de naturales y extranjeros, seguida con la ley de 4 de diciembre de 1866 sobre radicación y concesión de títulos de merced a los indígenas. Todo ello impulsó a establecer por ley de 1866 el cargo de "Protector de Indígenas", ante los graves atropellos cometidos contra la etnia, sus valores y recursos. La ins- titución que se extendió entre 1866 hasta 1930, denunció la ineficacia de las leyes en todos los ámbitos (Dávila 2002: 95-121; Comisión Parlamentaria de Colonización 1912). Desde 1883 se prohibió la adquisición de tierras indígenas. Y esta prohibición se fue prorrogando, desde el año 1893, por lapso de diez años, hasta los primeros años del siglo XX. El retroceso fue evidente en el desarrollo de la etnia mapuche (Bengoa 1987). Aun así, pudieron preservar su derecho consuetudinario ante la adversidad de los colonos y del propio Estado.

A esta idea de la expansión del territorio y del Estado, favorecido con el éxito en la guerra del Pacífico, se debe contrastar la realidad de los pueblos originarios del norte chileno. Estos, bajo el Estado boliviano, seguían siendo tributarios a la vieja usanza colonial (Núñez 1992, 2002 Ms; Gundermann 2002 Ms; Tudela 2002 Ms). El sur de Chile quedó sometido a la enajenación de tierras por comunidades étnicas, usurpaciones y atropellos, amparados por prejuicios e ideas racistas de nuevo cuño que, desgraciadamente, había alentado Benjamín Vicuña Mackenna. La "colonización" con elementos foráneos a la Araucanía fue la opción progresista e ilustrada del Estado.

El Estado liberal, con la fuerza del monismo jurídico (Irigoyen 1999), con la idea arraigada de "chilenizar es civilizar" como lo expusiese el presidente Balmaceda al Vicario Apostólico de Antofagasta monseñor Luis Silva Lezaeta, aplicó una política de homogeneizar a la nación chilena, mediante la escuela pública, el ejército y la propia Iglesia Católica (van Kessel 2003; González M. 2002; González P. 2002). Los rasgos inveterados de costumbres jurídicas fueron cuestionados y no reconocidos en su generalidad; se hizo normar todo el ámbito público indígena, su trabajo y el derecho de propiedad; se intervino en el sentido simbólico el recurso hídrico, se modificaron expresiones colectivas sobre la religiosidad, envuelta en un rico sincretismo espiritual, entre otros.

Se vivieron desde 1882 hasta 1924 años difíciles para la cultura y el respeto a los pueblos originarios. Todo se obnubiló bajo la idea del nuevo ídolo que era la modernidad. Y el Estado impulsó e impregnó todo con su sello. Las "reducciones" en el sur fueron la nueva fisonomía que fragmentó a las comunidades mapuches. 
La propagación de una cultura hegemónica basada en el código lógico racionalista supuso introducir, con la violencia pedagógica de los preceptores normalistas, la escritura, el libro, la gramática castellana en áreas donde dominaba lo ágrafo, lo oral y la tradición. El Estado no reparó en diferencias, máxime cuando el tema en algunas regiones se confundía con problemas de fronteras y de soberanía (p.e., la Araucanía, la hoya altiplánica de Antofagasta, los faldeos cordilleranos de Tarapacá y los fiordos magallánicos).

Estas incorporaciones de territorios, en la parte septentrional de Chile, significaron la territorialización de las leyes de la República en localidades y poblaciones aymaras y atacameñas.

Reparemos, por ejemplo, en que el fuerte positivismo jurídico que animaba las acciones jurisdiccionales estatales debió hacer frente al arraigado derecho consuetudinario atacameño. Dos fueron los temas más relevantes: la normativa sobre los derechos de aguas y el derecho de propiedad.

Entre 1890 y 1920 el Estado reconoció el derecho de las aguas indígenas en cuanto a sus turnos y caudal; empero, la autoridad pública determinó fijar mediante reglamentos la prioridad del uso consuntivo de las aguas, sin considerar el requerido de modo fundamental por las comunidades ancestrales. Lo prioritario fue el aprovisionamiento de agua para la minería y las localidades urbanas. En este marco, ríos y afluentes precordilleranos se vieron afectados por esta intervención administrativa desde 1913, siendo el uso del agua para las actividades agrícolas el menos favorecido, como lo establecía el "Reglamento relativo a las mercedes que se soliciten en el río Loa y sus afluentes y en las aguadas y vertientes de la provincia de Antofagasta" y refrendado por el "Reglamento sobre concesión de mercedes de aguas en el río Loa, sus afluentes, aguadas y vertientes de la provincia de Antofagasta" de 1920 (Tala Japaz y González P. 1996).

En la zona en referencia nuevamente se dieron cita dos concepciones sobre el uso del agua: la de la racionalidad instrumental occidental y la natural simbólica indígena. En este mismo contexto se asistió a un giro en la noción de "modernización" que significó que, a partir de 1925, el Estado asumiera la transformación del país, tanto en el plano de la infraestructura económica como de la creciente complejidad de su burocracia y del cuidado en las actividades económicas (González P. 1998).

Esta visión de la modernización vino a conjugar un papel preponderante a los ingenieros que laboraban para el Estado. Fueron ellos los que sentaron las bases de un Estado de carácter desarrollista. Concluida la tarea del binomio "chilenizar-civilizar", se impuso el de la racionalidad del uso de los suelos, de las aguas. Las obras viales, que se tradujeron en desvíos de cursos de aguas, proyectos de embalses, otorgamientos de nuevas concesiones de aguas para la minería, fueron el rostro de la modernización. El fundamento racional fue la búsqueda de solución para la salinidad de las aguas continentales y el apoyo a las inversiones que acrecentaran procesos de industrialización y explotación de recursos naturales de gran incidencia en el producto geográfico bruto (Albornoz 2001; Alegría y Valdés 2001; Castro 2001; González P. 2001).

Los resultados no se hicieron esperar: las vegas de Turi y las de Ojos de San Pedro se secaron. Tanto el río Loa como el Toconce se vieron explotados por las actividades mineras.

\section{El Estado de compromiso y el indigenismo estatal}

La instauración del denominado "Estado de compromiso" en nuestra carta constitucional de 1925 refrendó el compromiso de las clases sociales mesocráticas con las obreras. La ventilación del tema indígena quedó articulada en la generación de políticas públicas sociales sobre pobreza, regularización de títulos de dominio o promover agencias que cautelaran los derechos indígenas. Evidencia de ello fue lo establecido en febrero de 1930 al crearse cinco Juzgados de Indios "que procederían de oficio a dividir las comunidades indígenas que tengan título de merced”. Esta ley, la $\mathrm{N}^{\mathrm{o}} 4802$, declaraba de utilidad pública los terrenos restituidos o que deban restituirse a los indígenas conforme a las leyes sobre división de comunidades por los actuales ocupantes. Sin embargo, los indígenas podían enajenar o gravar el terreno comprendido en el título de merced.

La cuestión indígena derivó a insertar la problemática en torno a los grandes proyectos ideológicos que la sociedad chilena debatió durante el régimen democrático. 
Desde la óptica nacionalista, sus expositores, Keller o González von Marées, argumentaron que el asunto indígena incidía en las virtudes de la raza y por consiguiente debía integrarse como un todo en la nación; desde el prisma marxista, la cuestión indígena debía diluirse en la cuestión de clases, tal como lo había esbozado Stalin en la Cuestión Nacional. Hablar de la dicotomía indígena-nacional era esconder bajo la ideología burguesa, el tema de fondo que comprendía las relaciones sociales en los modos de producción; bajo la perspectiva social-cristiana se conjugaba el acento en la dignidad de la persona, cualquiera fuese su credo, su etnia y su raza, lo cual volvía a situar el tema indígena en las prestaciones asistenciales estatales.

El tema de la configuración del reconocimiento y su avance, podríamos decir dialéctico, volvía a sufrir un estancamiento de cara a la erección del Estado benefactor a fines de la década de 1930 Hacia 1953 con la creación de la Dirección de Asuntos Indígenas, el Estado asumió el denominado "indigenismo estatal". Como se sabe, fue una acción que coincidió con las políticas emprendidas por los Estados de mayoría étnica indígena en América Latina (Favre 1998).

Un reconocimiento provino desde la literatura que tomó el indigenismo, como una postura de hablar de los pueblos aborígenes, plantear su realidad paupérrima, su riqueza cultural: en el norte Neftalí Agrella toca el tema atacameño en "El alfarero indio"; el historiador del salitre, Oscar Bermúdez Miral incorporó al mundo licanantai en su novela "Pampa desnuda"; en el sur, autores como Fernando Santiván, Luis Durand, Marta Brunet, Daniel Belmar se extienden sobre las vicisitudes del pueblo mapuche. El principal poeta del norte, Andrés Sabella, recrea la materialidad de la cultura atacameña y la personalidad del pueblo mapuche.

Nuestras grandes voces líricas, Gabriela Mistral y Pablo Neruda, se sumaron de modo pleno a la reivindicación de los pueblos originarios. Había que ir en pos del hombre autóctono que había dado sentido a la ocupación del espacio telúrico americano.

La arqueología abrió paso a un reconocimiento más formidable, con José Toribio Medina, a las etnias del norte y sur de Chile; labor proseguida por Ricardo Latcham, Gustave Le Paige y los arqueólogos y antropólogos de la Universidad Católica del Norte. ${ }^{3}$ Es un reconocimiento que se agrega al gramatical emprendido, en el seno de los atacameños, por el sacerdote francés Emilio Vaïsse y el jurista Aníbal Echeverría y Reyes.

En el sur, para la etnia mapuche, se destaca la acción loable de Tomás Guevara; y para los fueguinos, la de Martin Gusinde. Un lituano, médico y antropólogo, empezó a difundir una obra denunciadora, hoy olvidada: Alejandro Lipschutz. ${ }^{4}$

Los historiadores Ricardo Donoso y Fanor Velasco enrostraron a las autoridades el despojo de la propiedad austral en su libro "Historia de la constitución de la propiedad austral", publicada en 1928.5

Esta problemática que hemos reseñado hizo que los derechos indígenas fueran visualizados desde dos ejes vectores. Por un lado, el Estado, entidad que debe velar por toda la población. No debemos olvidar, por ejemplo, que la creación de la CORFO, posiblemente la obra de mayor envergadura que ha concretado el Estado, fue para acrecentar la calidad de vida de todos los chilenos,

3 Consignemos en este lugar un acontecimiento de la mayor importancia. Cuando en el primer censo nacional al retorno de la democracia, en 1992, no se consignó a la etnia atacameña, sus miembros con sus dirigentes al frente acudieron al Instituto de Investigaciones Arqueológicas y Museo R. P. Gustavo Le Paige s. j., de la Universidad Católica del Norte, en busca de apoyo científico, tanto arqueológico, antropológico y documental, para poder "representar" al Estado de su existencia desde el tiempo prehispánico. Los respaldos académicos en aquella ocasión produjeron la rectificación del Gobierno de Chile y su ulterior condición de constituir parte de los pueblos originarios de la nación.

4 Martin Gusinde llegó a plantear que, si bien los yaganes pudieron establecer su "cultura primitiva" en las condiciones más adversas, los europeos hubieran fracasado. Alejandro Lipschutz hizo confluir sus observaciones médicoantropológicas con los análisis respecto a las condiciones sociales y económicas que la legislación del siglo $\mathrm{XX}$ coadyuvó a segregar o asimilar a las distintas comunidades indígenas en América Latina y en Chile.

5 Ha constituido, hasta el presente, el libro más polémico sobre la cuestión: fue retirado del comercio por decisión del gobierno militar de Carlos Ibáñez del Campo, como lesiva a los intereses del Estado. Fue publicada una segunda edición, bajo el título "La propiedad austral", por Icira en 1970, bajo el gobierno de Salvador Allende. 
mediante el proceso de industrialización. Por otro, la nación, referente que la Constitución Política le asigna el rol de depositaria de la soberanía.

De estas premisas sobre el Estado y la nación, que hemos señalado, es fácil colegir, entonces, que las obras tanto de Eduardo Frei M. como de Salvador Allende se enmarcaron, con el consabido espíritu de época, en los denominados por M. Góngora (1981) "proyectos globales excluyentes". Delineamientos ideológicos que no consideraron el tema indígena alejado del Estado y de la nación.

La iniciativa de la Reforma Agraria de 1967 abrió un replanteamiento de la propiedad agraria y se consideró la reivindicación mapuche; entretanto la etnia mapuche se había estructurado en la Confederación Nacional de Asociaciones Mapuches en 1969.

El Instituto de Desarrollo Indígena, establecido en septiembre de 1972, tuvo por objetivo: promover el desarrollo social, económico, educacional y cultural de los indígenas y procurar su integración a la comunidad nacional, considerando su idiosincrasia y respetando sus costumbres (Stavenhagen 1988). Aun así, se recuperaron para las comunidades mapuches 68381 ha.

\section{Desde el giro copernicano de 1978-79 hasta la nueva institucionalidad indígena de 1993}

Los sucesos de 1973 no sólo significaron retrotraer la situación indígena hacia la noción de la propiedad privada sino forjar una nueva institucionalidad. El Decreto Ley No 2568 de 1978 sobre división de las reservas rezaba que "dejarán de considerarse tierras indígenas e indígenas sus dueños y adjudicatarios". Cuyo tremendo impacto llevó a su reforma por el Decreto Ley $\mathrm{N}^{\circ} 2750$ de 1979, modificación radical donde el Estado benefactor se deshacía y emergía el mercado como el orientador de las asignaciones de agua y la configuración de la propiedad. Era el Estado liberal mínimo, preconizado por Hayek y Friedmann. El impacto de estas normativas en el mundo indígena fue devastador, llegándose a considerar que los referidos Decretos Leyes constituyeron la "legislación etnocida del régimen militar" (Aylwin 1989). Se ha calculado que entre 1979 y 1986 la división de las comunidades indígenas mapuches afectó al 59.6\% del total existente entre Arauco y Osorno.
A la legislación propiamente indígena incidió la promulgación del nuevo Código de Aguas de 1981 que reforzó el derecho individual y el acceso de los particulares a los recursos hídricos mediante el derecho de aprovechamiento.

Importa destacar que en los últimos lustros bajo la institucionalidad de la Carta de 1980 se va a reforzar, por un lado, el criterio Estado-nación en las denominadas "Bases de la Institucionalidad", al referirse a "los integrantes de la comunidad nacional" o a que el Estado debe "promover la integración armónica de todos los sectores de la nación", como se establece en su artículo 1.

Con el retorno a la democracia en 1990, la normativa nacional va a considerar los adelantos del Derecho Internacional en los asuntos indígenas. En este ámbito, se van a estudiar los nuevos instrumentos legales promovidos por los foros internacionales. De modo sucinto, se van a tomar en cuenta la "Declaración de Principios de Derechos Indígenas" de 1984, que avanzaba sobre las dos cuestiones fundamentales exigidas por los pueblos originarios: los derechos territoriales (protección y control de sus tierras, territorios y recursos naturales tradicionales) y los derechos políticos (derecho a participar en las decisiones que le afectaban, gobernarse de acuerdo a sus propias leyes e instituciones); los avances en el seno del Instituto Indigenista Interamericano y su Convenio, surgido en 1940; como, de igual modo, lo formulado por el Sistema Interamericano de Derechos Humanos, tanto en sus órganos de la Comisión como de la Corte; lo resuelto por la O.E.A. con la "Declaración Interamericana sobre los Derechos de los Pueblos Indígenas", de septiembre de 1995 y, fundamentalmente, en los organismos de las Naciones Unidas, como el Grupo de Trabajo de Poblaciones Indígenas, surgido en 1982, y la propuesta de erigir un Foro permanente de Naciones Unidas para los Pueblos Indígenas, aprobado en 1998 (Aylwin 2003 Ms), o la Organización Internacional del Trabajo (O.I.T.) con el Convenio 107 de 1957 sobre Protección e Integración de Poblaciones Indígenas y otras Poblaciones Tribales y Semitribales de Países Independientes y su sustantiva modificación en 1989 con el Convenio 169 sobre Pueblos Indígenas y Tribales en Países Independientes, incorporando la noción de "pueblos indígenas" (Correa $2002 \mathrm{Ms}$ ); o bien la Conferencia de las Naciones Unidas sobre Medio Ambiente y Desarrollo, que en Río de Janeiro en 
1992 aprobó la "Agenda 21", cuyo capítulo 26 reconoce y fortifica el rol de los pueblos originarios y, finalmente, el acuerdo de las Naciones Unidas en julio de 1993 sobre el "Proyecto de Declaración sobre los Derechos de las Poblaciones Indígenas", que vuelve a insistir sobre los derechos políticos y territoriales. Instrumentos que obligarán, al ser suscrito por Chile, salvo el Convenio 169 , a debatir la supremacía constitucional respecto de los convenios internacionales.

Estos instrumentos internacionales, interesantes en varios aspectos, relacionados con los derechos de los pueblos originarios, si bien fueron recepcionados en los medios políticos y juristas nacionales, debieron acomodarse al momento político de tránsito hacia la nueva institucionalidad democrática y a la política de los acuerdos. De ahí, que su discusión e influencia en la legislación nacional fue de desigual impacto en las medidas a favor de los pueblos indígenas.

Desde 1989 un sector importante de la representación política nacional había avanzado en Nueva Imperial medidas a favor de los pueblos originarios. Ya en el poder político, bajo el gobierno del presidente Patricio Aylwin, va a promocionar llevar a la práctica estos acuerdos, por medio de la Comisión Especial de Pueblos Indígenas. Así, desde el Estado se incentivó una nueva relación con los pueblos originarios, bajo la Ley Indígena -la 19253- sobre "Protección, Fomento y Desarrollo de los Indígenas", de septiembre de 1993. En ella se lee en su artículo 1:

"El Estado reconoce que los indígenas de Chile son los descendientes de las agrupaciones humanas que existen en el territorio nacional desde tiempos precolombinos, que conservan manifestaciones étnicas y culturales propias siendo para ellos la tierra el fundamento principal de su existencia y cultura".

Más adelante, en el artículo 7, refiere:

"El Estado reconoce el derecho de los indígenas a mantener y desarrollar sus propias manifestaciones culturales, en todo lo que no se oponga a la moral, a las buenas costumbres y al orden público".

Y puede percibirse un relativo avance hacia el reconocimiento en el campo jurídico, al estam- par, en el artículo 54, "La costumbre hecha valer en juicio entre indígenas pertenecientes a una misma etnia, constituirá derecho, siempre que no sea incompatible con la Constitución Política de la República”.

El establecimiento de la Corporación Nacional de Desarrollo Indígena (CONADI), en la misma ley en comento, ha significado avanzar en la asociación de la tierra y los recursos hídricos habidos en el territorio considerado históricamente ocupado desde tiempos prehispánicos con continuidad histórica, por la etnia. ${ }^{6}$

Esta línea de continuidad en lo jurídico que exhibe el Estado desde las distintas formulaciones teóricas, se ha visto fuertemente interpelada con la emergencia de nuevos temas de la agenda política internacional. Es la cuestión larvada que se ha visto arrastrada en el curso de los años en la dicotomía, expuesta por Habermas, respecto a la visión liberal que determina el estatus de los ciudadanos por los derechos negativos que tiene frente al Estado y otros ciudadanos, y la mirada republicana donde los derechos políticos, que el autor asigna a los derechos de participación y comunicación política, constituyen libertades positivas. De ahí, su planteamiento de un "acuerdo comunicativo" que posibilitaría entender los derechos humanos como condiciones donde las diversas formas de comunicación necesarias se expondrían para la elaboración de la ley (Habermas 1998: 267280). El otro factor es la irrupción del multiculturalismo que se hace cargo de las opciones legítimas de las conexiones culturales propias de grupos étnicos (Bengoa 2000).

En este marco, las reivindicaciones étnicas de suyo legítimas desde su origen, en cuanto a considerar sus marcos regulatorios en el aprovechamiento de los recursos naturales y en el ejercicio de sus facultades, deben justipreciarse como el término cabal del reconocimiento por fin no sólo de su identidad diferencial, sino de la existencia de otro que posee una arqueología de experiencia y un saber integrarse en el eje tiempo-espacio, en un territorio que es compartido por otros.

\footnotetext{
6 En marzo de 1997 el Estado declaró "áreas de desarrollo indígenas" específicos lugares del territorio nacional; en junio de 1998 declaró el día 24 de junio de cada año "Día Nacional de los Pueblos Indígenas".
} 
Comprender aquello es asumir de modo lógico y congruente la propia evolución de los derechos humanos en el devenir histórico y en nuestra patria, pues, huelga decir, no basta con los intentos de modificar la fórmula constitucional como se presenta y se define el Estado, como, por ejemplo, la iniciativa del senador Silva Cimma de incorporar en el artículo 4 que "Chile es un Estado social y democrático de derecho". En esa misma oportunidad, la Comisión de Constitución, Legislación y Justicia y Reglamento del Senado, en noviembre de 2002, rechazó incorporar la expresión de "pueblos indígenas" a pesar de existir un fallo del Tribunal Constitucional respecto a poder acogerse el Convenio No 169 sobre Pueblos Indígenas y Tribales, adoptado por la O.I.T. el 27 de junio de 1989, por no contravenir las "bases de la institucionalidad".

La Comisión respectiva aprobó en aquella ocasión intercalar en el artículo 1:

"La nación chilena es indivisible. El Estado reconoce la diversidad de origen de los chilenos que forman parte de la nación y declara su especial preocupación por las poblaciones indígenas originarias, a las cuales garantiza su derecho a fortalecer los rasgos esenciales de su identidad" (Comisión de Constitución, Legislación, Justicia y Reglamento del Senado 2001: 29-54).

Se puede apreciar en esa declaración algo de temor de fragmentar la soberanía y proseguir con la noción de Estado-nación más flexible; en todo caso, distante a lo que ha propuesto la Comisión de Verdad Histórica y Nuevo Trato, formada en enero de 2001 y cuyo Informe entregó en octubre de 2003. En este Informe refiere que la relación del Estado con los pueblos indígenas en el pasado fue el de negar la identidad y existencia de éstos a favor de una identidad nacional única y la apropiación del territorio indígena a favor de la consolidación del Estado. La formación exitosa del Estado-nación chileno se tradujo para los pueblos indígenas en su reducción territorial, la fragmentación social, la pérdida patrimonial, la pérdida de la vigencia de sus sistemas normativos propios e idiomas e, incluso, la desaparición de pueblos indígenas enteros (p.e., aónikenk y selk'nam). De ahí, la necesidad de rectificar la acción estatal y plantear un nuevo "trato". La segunda parte de este Informe, "Propuestas y recomendaciones para un nuevo trato entre el Estado, los pueblos indígenas y la sociedad chilena" expone que:

"Nuestra cohesión como comunidad nacional, nuestras posibilidades de desarrollo, nuestra inserción en un mundo sometido a procesos de globalización de envergadura y alcance planetario, no se forjan erigiendo nuestra identidad y nuestros proyectos de futuro sobre la base de continuar afirmando que la verdad de unos está por sobre la verdad de otros" (Comisión Verdad Histórica y Nuevo Trato 2003).

El nuevo trato se debe inspirar "en el respeto, la equidad, el mutuo reconocimiento, la justicia y la dignidad de todos sus miembros" que se estiman fundamentales para la convivencia nacional. ${ }^{7}$

\section{Conclusión}

Puede considerarse que en la actualidad se ha retomado -en lo programático de la agenda estatal- la senda original que los forjadores de la República asignaron a los pueblos originarios: la igualdad jurídica y el respeto a su idiosincrasia, no sólo como un mandato legal sino por una razón ética de mayor fuerza, ser los hermanos y los primeros en la nación chilena.

Empero, los cambios operados en el escenario internacional (el multiculturalismo, la agenda de los derechos humanos y el proceso de globalización) han modificado los debates al respecto, pues no sólo han constituido referentes para la vida social y jurídica nacional, sino incidencias que han supuesto posibilidades y desafíos para los pueblos originarios.

En este contexto, podemos mencionar como temas pendientes y expectativas: la conciliación de los tópicos de derechos humanos y la situación de las etnias originarias (Stavenhagen 1989), la adecuación de la reforma procesal penal y el sis-

\footnotetext{
7 Una arista del problema de los derechos indígenas en nuestra realidad jurídica que se evidenció en la discusión parlamentaria sobre el Convenio 169 y volvió a plantearse en la Comisión Verdad Histórica y Nuevo Trato, es la discrepancia en cómo deben asumirse éstos: una postura se inclina por un reconocimiento colectivo de ellos (Instituto de Estudios Indígenas 2002; Comisión Verdad Histórica y Nuevo Trato 2003), en tanto otra considera que el reconocimiento debe ser individual en la senda de la tradición constitucional liberal (Sierra 2003).
} 
tema de resolución y negociación judicial en el mundo indígena (Lillo Vera 2001), las acciones de los TLC y el Convenio de Biodiversidad y su impacto sobre los derechos de propiedad intelectual y especialmente sobre los derechos de obtentores de variedades vegetales (Toledo 2004 Ms); pero, también, se ha avanzado de modo decidido en el reconocimiento a los derechos ancestrales a las aguas (Sentencia Corte Suprema, 22 de marzo de 2004), lo que ha sido interpretado como el reconocimiento del derecho al agua como derecho humano (Vallemar 2004).

Sin embargo, en los avances experimentados desde 1990 a la fecha, en materias legales y socioeconómicas, quedan aspectos casi estructurales, que siguen gravitando sobre los pueblos originarios. No a todos por igual. El pueblo mapuche, por su complejidad en el tejido socio-histórico de las acciones estatales que le han afectado, exhibe una mayor demanda al Estado. En esta perspectiva, como lo ha referido el Relator de las Naciones Unidas, Rodolfo Stavenhagen, "los derechos sobre la propiedad de la tierra y la territorialidad constituyen uno de los problemas históricos más graves que afectan a los pueblos indígenas de Chile", agudizados en puntuales aspectos, como, por ejemplo, el acceso a los recursos del subsuelo y agua, los recursos ictiológicos, la explotación forestal, la correlación entre pobreza e identidad indígenas, los niveles de conflictividad en las regiones VIII, IX y X (Stavenhagen 2004).

En este panorama es muy sensible, como lo hace ver Stavenhagen, que la Ley Indígena de 1993 no contemple adecuadamente "los mecanismos de protección de los derechos humanos de los pueblos indígenas" que para el Relator pudiese subsanarse en gran medida con la adopción del Convenio 169 de la O.I.T., instrumento legal que ha sido considerado como el paso fundamental que el Estado debería dar en pos del reconocimiento de los pueblos indígenas. Nuestra situación en el Derecho Internacional comparado deja bastante que desear si lo analizamos respecto a los países latinoamericanos con contingente mayoritario, importante, o escaso, de población indígena. Esto lo ha puesto de relieve la Comisión Andina de Juristas en su trabajo "Los Derechos Humanos en las Constituciones Andinas. Derechos de los Pueblos Indígenas" donde, de 13 materias, sólo en aquellas generales Chile aparece posibilitando el derecho a la participación política, el derecho de no discriminación por pertenencia a pueblos indígenas, etnia o raza; autorización y consulta para la explotación de recursos naturales, medio ambiente, propiedad intelectual, derecho a no ser desplazados de sus tierras y derecho a la participación política en general.

La autocomprensión colectiva exige a la sociedad chilena abordar definitivamente el reconocimiento constitucional de los pueblos indígenas. La propia experiencia comparativa en nuestro continente permite buscar fórmulas constitucionales pertinentes, desde el marco dado por Argentina hasta lo otorgado por México.

De esta manera, en la noción de Nación integraremos la otra parte de la base genética de nuestra sociedad, que el Estado deberá proteger y dejar desarrollarse.

\section{REFERENCIAS CITADAS}

AGRELLA, N., 1966. El alfarero indio. En Antología del cuento nortino, M. Bahamonde (Ed.), pp. 140-147. Editorial Universitaria, Santiago.

ALBORNOZ, P., 2001. Los derechos de aprovechamiento de aguas indígenas. El caso de las etnias aymara, atacameña y mapuche. Revista de Derecho Administrativo, Económico de Recursos Naturales 3 (2): 317-330.

ALEGRIA, M. A. y F. P. VALDES, 2001. El agua y los pueblos originarios aymaras y atacameños. Revista de Derecho Administrativo, Económico de Recursos Naturales 3 (2): 333-344.
ANGUITA, R., 1912. Leyes promulgadas en Chile desde 1810 hasta el 1 de junio de 1912. Imprenta, Litografía i Encuadernación Barcelona, Santiago.

AYLWIN, J., 1989. Tierra mapuche: Derecho consuetudinario y legislación chilena. América Indígena 49 (2): 369 391.

_-2003 Ms. Reconocimiento de los derechos de los pueblos indígenas. Cap. VI del Informe Final del Grupo de Trabajo Legislación e Institucionalidad. Documento CVHNT/ GT DER/2003/116. Santiago. 
BENGOA, J., 1987. Historia del pueblo mapuche (siglos XIX yXX). Editorial Sur, Santiago.

2000. La emergencia indígena en América Latina. Fondo de Cultura Económica, Santiago.

BERMUDEZ, O., 1950 Ms. Pampa desnuda. Novela inédita.

CASTRO, M., 2001. El agua en derecho consuetudinario de aymaras y atacameños, del norte de Chile. Revista de Derecho Administrativo, Económico de Recursos Naturales 3 (2): 345-354.

COMISION VERDAD HISTORICA Y NUEVO TRATO, 2003. Acta Sesión del 2 de diciembre de 2002. Subcomisión Legislativa. Documento Oficial CVHNT/SE/2003/ 102. Santiago.

CORREA, R., 2002 Ms. Informe de constitucionalidad Convenio 169 sobre Pueblos Indígenas y Tribales en países independientes, de la O.I.T. Comisión de Verdad Histórica y Nuevo Trato. Subcomisión de Legislación. Documento de Trabajo CVHNT/GTDER/2002/053. Santiago.

COMISION ANDINA DE JURISTAS. Los derechos humanos en las constituciones andinas. Derechos de los pueblos indígenas. http://www.cajpe.org.pe

COMISION DE CONSTITUCION, LEGISLACION, JUSTICIA Y REGLAMENTO DEL SENADO, 2001. Reforma a la Constitución Política de la República de 1980. Noviembre s.p.i.

COMISION PARLAMENTARIA DE COLONIZACION, 1912. Informe, proyectos de ley, actas de las sesiones y otros antecedentes. Imprenta y Litografía Universo, Santiago.

DAVILA, O., 2002. Vida jurídica práctica contenida en los informes de los Protectores de indígenas en Chile (18661930). Anuario Iberoamericano de Historia del Derecho e Historia Contemporánea 2: 95-121.

DONOSO, R. y F. VELASCO, 1928. Historia de la constitución de la propiedad austral. Imprenta Cervantes, Santiago.

1970. La propiedad austral. Icira, Santiago.

FAVRE, H., 1998. El indigenismo. Fondo de Cultura Económica, México D. F.

GONGORA, M., 1981. Ensayo histórico sobre la noción de Estado en Chile en los siglos XIX y XX. Editorial La Ciudad, Santiago.

GONZALEZ M., S., 2002. Chilenizando a Tunupa. La escuela pública en el Tarapacá andino (1880-1990). DIBAM y Universidad Arturo Prat, Santiago.

GONZALEZ P., J. A., 1990. Claudio Gay y la historiografía chilena. El contexto histórico-cultural en la formulación de una concepción historiográfica. Revista Chilena de Historia y Geografía 158: 103-125.
_ 1996. Notas sobre el Estado, la nación e identidad nacional durante el siglo XIX en Chile. Anuario de la Facultad de Ciencias Jurídicas de la Universidad de Antofagasta, pp.47-65.

_ 1998. El régimen jurídico prehispánico sobre las aguas y su inserción en el derecho indiano. Algunas observaciones. Seminario Realidad y Proyección del Derecho de Aguas. Facultad de Ciencias Jurídicas, Universidad de Antofagasta, pp.39-62. Editorial Sergraf, Antofagasta.

2001. La salinidad de las aguas continentales y los proyectos hidráulicos de fines del siglo XIX y principios del siglo XX en la Región de Antofagasta. Revista de Derecho Administrativo, Económico de Recursos Naturales 3 (2): 401-411.

2002. El catolicismo en el Desierto de Atacama. Iglesia, sociedad, cultura (1557-1987). Ediciones Universitarias, Universidad Católica del Norte, Antofagasta.

GUNDERMANN, H., 2002 Ms. Sociedad aymara y procesos de modernización durante la segunda mitad del siglo XX Comisión de Verdad Histórica y Nuevo Trato. Grupo de Trabajo Pueblos Indígenas del Norte Documento CVHNT/ GTPIN/2002/038. San Pedro de Atacama,

GUSINDE, M., 2000. Los fueguinos. Biblioteca Virtual Miguel de Cervantes. http://www.cervantesvirtual.com

GUZMAN, A., 1982. Andrés Bello codificador. Historia de la fijación y codificación del derecho civil en Chile. Ediciones de la Universidad de Chile, Santiago.

HABERMAS, J., 1998. Derechos humanos y soberanía popular. Las versiones liberal y republicana. En La democracia en sus textos, R. del Aguila, J. A. de Gabriel, E. García Guitián, A. Rivero y F. Vallespín (Eds.), pp. $267-$ 280. Alianza Editorial, Madrid.

INSTITUTO DE ESTUDIOS INDIGENAS, 2002. Pueblos indígenas, reforma constitucional y violencia en la Araucanía. Universidad de la Frontera, Temuco.

IRIGOYEN, R., 1999. El reconocimiento constitucional del derecho indígena en los países andinos, En El reto a la diversidad. Pueblos indígenas y reforma del Estado en América Latina, W. Assies, G. van den Haar y A. Hoekema (Eds.), pp. 343-380. El Colegio de Michoacán, Zamora.

LARRAIN, J., 2001. Identidad chilena. Ediciones Lom, Santiago.

LEVAGGI, A., 2002. Diplomacia hispano-indígena en las fronteras de América. Centro de Estudios Políticos y Constitucionales, Madrid.

LILLO VERA, R., 2001. Los derechos de los indígenas y el nuevo sistema procesal penal. Revista de Derecho 2: 87136.

NUÑEZ, L., 1992. Cultura y conflicto en los oasis de San Pedro de Atacama. Editorial Universitaria, Santiago. 


\section{JOSE ANTONIO GONZALEZ P.}

-2002 Ms. Breve historia de los pueblos atacameños. Desde la prehistoria a los comienzos del siglo 19. Comisión de Verdad Histórica y Nuevo Trato. Grupo de Trabajo Pueblos Indígenas del Norte Documento CVHNT/ GTPIN/2.002/059. San Pedro de Atacama.

PINTO, J., 2003. La formación del Estado y la nación, y el pueblo mapuche. De la inclusión a la exclusión. DIBAM - Centro de Investigaciones Diego Barros Arana, Santiago.

SENTENCIA de la Excelentísima Corte Suprema de Justicia, de fecha 22 de marzo de 2004, la causa Comunidad Atacameña Toconce con Essan S. A., Rol. Ex. Corte $\mathrm{N}^{\circ}$ 986-03. www.poderjudicial.cl

SIERRA, L., 2003. La Constitución y los indígenas en Chile: Reconocimiento individual y no colectivo. Estudios Públicos 92: 19-27.

STAVENHAGEN, R., 1988. Derecho indígena y derechos humanos en América Latina. El Colegio de México Instituto Interamericano de Derechos Humanos, México D. F.

-1989. Derecho consuetudinario indígena en América Latina. América Indígena 49 (2): 223-243.

2004. Derechos humanos y cuestiones indígenas: Informe del Relator sobre la situación de los derechos humanos y las libertades fundamentales Sr. Rodolfo Stavenhagen, presentado de conformidad con la resolución 2001/57 de la Comisión Adición Misión Chile. E/ CN.4/2.004/80/ Add.3. 17 de noviembre de 2003.
SZASZDI, I. y E. PALMA, 1998. El parlamento hispanoaraucano de 1641: Naturaleza jurídica de un pacto internacional. Libro Homenaje in Memoriam Carlos Díaz de Rementería. Universidad de Huelva, Huelva.

TALA JAPAZ, A. y J. A. GONZALEZ P., 1996. Admisibilidad jurídica de un estatuto diferencial para el régimen de las aguas continentales en la Segunda Región de Chile. Revista de Derecho año 3, pp.101-176.

TOLEDO, V., 2004 Ms. Derechos de propiedad intelectual y derechos de los pueblos indígenas. Impactos locales de normas globales. Alianza Chilena por un Comercio Justo y Responsable (ACJR), Santiago.

TUDELA, P., 2002 Ms. El Estado y sociedad chilena ante los aymaras de Tarapacá (I Región de Chile): Factores y consecuencias de su integración entre 1930-1973. Comisión de Verdad Histórica y Nuevo Trato. Grupo de Trabajo Pueblos Indígenas del Norte. Documento de Trabajo Interno CVHNT/GTPIN/2002/024. Santiago.

VALENCIA, L., 1986. Anales de la República. Textos constitucionales de Chile y registro de los ciudadanos que han integrado los poderes ejecutivo y legislativo desde 1810. Editorial Andrés Bello, Santiago.

VALLEMAR, K., 2004. El derecho al agua y los pueblos indígenas: A propósito de una sentencia de la Corte $\mathrm{Su}$ prema de Justicia de Chile. Comisión Andina de Juristas. http://www.cajpe.org.pe

VAN KESSEL, J., 2003. Holocausto al progreso. Los aymaras de Tarapacá. IECTA, Iquique. 